CURRENT TREATMENT ALGORITHM

\title{
Core binding factor acute myelogenous leukemia-2021 treatment algorithm
}

\author{
Gautam Borthakur (iD ${ }^{1 凶}$ and Hagop Kantarjian (iD) ${ }^{1}$
}

(c) The Author(s) 2021

Core binding factor acute myelogenous leukemia (CBF-AML), characterized by the presence of either $\mathrm{t}(8 ; 21)(\mathrm{q} 22 ; \mathrm{q} 22)$ or inv(16) $(p 13 q 22) / t(16 ; 16)$, is considered good-risk AML in the context of cytarabine based intensive chemotherapy. Still, outcome can be improved significantly through the effective implementation of available therapeutic measures and appropriate disease monitoring. The incorporation of gemtuzumab ozogamicin into frontline therapy should be standard. Cytarabine based induction/ consolidation regimen may be combined with anthracycline $(3+7$ standard) or antimetabolite, fludarabine. Serial quantitative polymerase chain reaction (QPCR) monitoring of unique fusion transcripts allows monitoring for measurable residual disease clearance; this allows for better prognostication and well as treatment modifications.

Blood Cancer Journal (2021)11:114; https://doi.org/10.1038/s41408-021-00503-6

\section{BACKGROUND}

Core-binding factor (CBF) acute myeloid leukemia (AML), comprising up to $12-15 \%$ of all $A M L$ cases $[1-5]$, is characterized by the presence of either $t(8 ; 21)(q 22 ; q 22)$ or inv(16)(p13q22)/t(16;16), which leads to the formation of RUNX1/RUNX1T1 (AML1/ETO) [6] and CBFB/MYH11 [7] fusion genes respectively. These cytogenetic aberrations are associated with favorable response and increased sensitivity to cytarabine. However, long-term follow-up reports from larger groups show a median overall survival (OS) of $\sim 5$ years or less $[1,8-10]$, indicating the need to improve therapy further. The population-based SEER data from 2000 to 2010 reports a 3-year OS rate of $57.3 \%$ for patients with inv(16), but only $35.5 \%$ in $t(8 ; 21)$.This suggests the possibility of substantial improvement of outcome in both AML entities.

\section{PATHOGENESIS}

Core binding factors are hematopoietic transcription factors characterized by heterodimers of two units: a DNA binding unit, and a CBFA and non-DNA binding unit, CBFB (reviewed in Speck and Gilliland [11]). CBFA comprises of three subunits; RUNX1, RUNX2, and RUNX3, while CBFB is invariate and is the non-DNA binding unit of the heterodimer. Core binding factors are necessary in normal hematopoiesis. Translocation events alter the normal DNA binding of the heterodimer and create alternate binding, leading to disruption of the normal transcription program and resulting in maturation arrest [12]. For example, the fusion protein AML/ETO negatively impacts the myeloid differentiation promoting transcriptional effect of PU1 by binding and displacing the coactivator c-Jun from PU1 [13].

The unique translocation event is likely not enough for leukemogenesis and additional mutational events involving epigenetic/chromatin modulators (e.g. TET2, ASXL1, ASXL2), kinases (e.g. $F L T 3, R A S$ ) and others are needed for leukemic development and progression [14, 15]. The overall mutational burden is however lower in CBF AML compared to intermediate or high risk $\mathrm{AML}[14,16]$.

\section{T(8;21) AND INV16 AML- ARE THEY TWO DIFFERENT DISEASES?}

Though both $\mathrm{t}(8 ; 21)$ and inv16 AML involve CBF translocations and are considered good-risk $A M L$, outcomes of $t(8 ; 21)$ and inv16 are quite different. While remission rates are similarly high, relapses are more frequent in the $\mathrm{t}(8 ; 21) \mathrm{AML}$ and long-term outcome is worse [17]. The co-operating mutational profiles are also different: $t(8 ; 21)$ AML is associated more often with epigenetic/chromatin modulator/cohesion mutations while inv16 AML is associated more often with kinase mutations [14, 16, 18], particularly MAPK pathway mutations. Epigenetic mutations are relatively infrequent in inv16 AML.

Interestingly, multiple mutations in the same signaling pathway are frequent in CBF AML, which indicates clonal interference or parallel evolution. The presence of clonal interference does not impact remission or measurable residual disease (MRD) clearance, but may be associated with inferior event-free survival (EFS) [19].

\section{OPTIMIZING REMISSION INDUCTION THERAPY IN CBF AML}

Remission rates are usually high in CBF AML. Remission induction with cytarabine/anthracycline-based chemotherapy combinations and consolidation with high-dose cytarabine (HDAC)-based regimens is considered as the standard of care for AML. However, in addition to complete morphological remission (CR), the depth of remission is important as several studies have shown that early reduction in the CBF related fusion transcript translates into better relapse-free survival (RFS) [20-22].

${ }^{1}$ Department of Leukemia, MD Anderson Cancer Center, Houston, TX, USA. ${ }^{{ }}$email: gborthak@mdanderson.org

Received: 29 January 2021 Revised: 29 March 2021 Accepted: 24 May 2021

Published online: 16 June 2021 
Fludarabine, cytarabine and GCSF (FLAG)-based regimens can be effective alternative to the traditional " $3+7$ " based approach [2325]. CBF AML is considered sensitive to cytarabine and the sequential administration of fludarabine followed by cytarabine allows increased ara-CTP accumulation in AML blasts [26]. This rationale led to the investigation of adding fludarabine to cytarabine based regimens with or without anthracycline in CBF AML.

We reported an analysis of non-randomized data from 114 patients with CBF AML treated at MD Anderson with the following induction regimens: (1) fludarabine and cytarabine (FA) $(n=45)$; (2) FA with G-CSF (FLAG) $(n=22)$; and (3) idarubicin and cytarabine with or without GCSF (IA or IAG) $(N=47)$. A multivariate analysis showed that the FLAG regimen was associated with longer event-free survival (EFS) than IA/IAG with a relative risk (RR) of 0.47 (FLAG vs. IA/IAG; $p=0.07$ ). The EFS was similar with FA and IA/IAG $[R R=0.84 \mathrm{FA}$ vs. IA/IAG, $p=0.58)]$. A post hoc analysis of the Medical research Council (MRC) AML15 randomized trial showed that patients with CBF AML who completed two courses of FLAG and idarubicin (FLAG-IDA) followed by 2 courses of HDAC had the best long term survival $[25,27]$.

\section{ADDITION OF GEMTUZUMAB OZOGAMICIN TO REMISSION INDUCTION THERAPY}

A meta-analysis of five randomized trials showed that the addition of Gemtuzumab Ozogamicin (GO) to remission induction therapy improved survival in CBF AML, with an absolute survival benefit of $20.7 \%$ (OR 0.47, 0.31-0.73; $p=0.0006$ ) [28], even though remission rates were not higher with $\mathrm{GO}$ containing regimens. The largest benefits were observed in the studies that used lower doses of GO $\left(3 \mathrm{mg} / \mathrm{m}^{2}\right.$ : MRC trial) or fractionated doses of $\mathrm{GO}\left(3 \mathrm{mg} / \mathrm{m}^{2}\right.$ on Days 1, 3, and 5: ALFA trial) compared with GO $6 \mathrm{mg} / \mathrm{m}^{2}$, We reported 3-year OS and RFS rates of $78 \%$ and $85 \%$ respectively in an ongoing study of FLAG-GO $\left(3 \mathrm{mg} / \mathrm{m}^{2}\right.$ of $\mathrm{GO}$ single dose in induction) [23]. Thus, the incorporation of $G O$ into the remission induction should be considered standard for CBF AML.

\section{OPTIMIZING THE POST-REMISSION THERAPY IN CBF AML}

A retrospective analysis of four successive CALGB trials included 50 patients with $t(8 ; 21)$ [29]. As consolidation, either three cycles or more of HDAC or one cycle of HDAC was administered, followed by additional non-cytarabine based post-remission therapy. Consolidation therapy consisting of 3 or 4 cycles of HDAC $(n=21)$ was associated with a lower relapse rate and a better OS compared with one course of HDAC $(n=29)$. A similar report from the CALGB group that included 48 patients with inv $(16) / t(16 ; 16) A M L$ under 60 years showed also a significantly lower 5 -year relapse rate with 3 or 4 cycles of HDAC $(n=28)$ compared with one course of HDAC $(n=$ 20) in consolidation [30]. A more recent report from CALBG confirmed that among younger patients ( $<60$ years) with CBF-AML, those treated with multicourse HDAC $(n=149)$ in remission were less likely to relapse $(P<0.001)$ compared to ones treated with a single course of HDAC ( $n=48)$ [17].

Another way of addressing the optimal dose of post-remission cytarabine is to look at total cumulative dose of cytarabine. The pooled data from multiple German trials could not demonstrate a difference in outcome among cumulative doses of cytarabine that ranged from $20.8 \mathrm{~g} / \mathrm{m}^{2}$ to $56.8 \mathrm{~g} / \mathrm{m}^{2}$ [10]. In the CALGB studies, the outcome of patients receiving four cycles of intermediate dose cytarabine (IDAC) consolidation (cumulative infusional cytarabine dose of $8 \mathrm{gm} / \mathrm{m}^{2}$ ) and 3-4 cycles of HDAC (cumulative bolus cytarabine dose of $54-72 \mathrm{gm} / \mathrm{m}^{2}$ ) were similar [17]. A French AML Intergroup study also did not show any difference in outcome between IDAC and HDAC groups [31]. Thus, even though post-remission age-adjusted multi-cycle HDAC is considered standard, the optimal dose of cytarabine remains to be determined.

\section{ARE ANTHRACYCLINES NEEDED IN CBF AML}

In the MRC 15 trial, the FLAG-IDA regimen was toxic and resulted in increased rates of myelosuppression and deaths in remission, even though the idarubicin dose was $8 \mathrm{mg} / \mathrm{m}^{2}$ (not the usual $12 \mathrm{mg} / \mathrm{m}^{2}$ ) [25]. In the daunorubicin intensification study conducted by Eastern Cooperative Oncology Group (ECOG) Leukemia committee using a " $3+7$ " based regimen, the daunorubicin intensification did not improve the outcome among patients with CBF AML [2].

\section{QUANTITATIVE MONITORING OF MEASURABLE RESIDUAL DISEASE IN CBF AML AND MRD-BASED DECISION MAKING}

The presence of unique transcripts allows for quantitative polymerase chain based (QPCR) monitoring of MRD in CBF AML. The data from multiple studies have confirmed the utility of MRD monitoring by QPCR in identifying differences in patients' outcomes. [20, 21, 32, 33]. Early transcript reductions at the end of remission induction or after few courses of consolidation are predictive of improved RFS. The MRC group reported that a $>3$ log reduction in RUNX1-RUNX1T1 transcripts in the bone marrow in $\mathrm{t}$ $(8 ; 21) A M L$ at end of induction, predicted for better RFS; the cumulative incidence of relapse (CIR) was $4 \%$ among the $47 \%$ of patients who achieved this MRD level versus 32\% among those who did not. Similarly, $a<10$ CBFB-MYH11 copy number in peripheral blood (PB), normalized to $10^{5}$ copies of $A B L$, in inv(16) predicted for CIR of $21 \%$ among the $57 \%$ who achieved it versus $50 \%$ among the patients who did not. The data from MD Anderson showed that $a \geq 3 \log$ reduction of transcripts in the bone marrow at end of induction and $a \geq 4$ log reduction after 2-3 courses of consolidation best predicted for better RFS [20]. While flowcytometry based MRD monitoring could be useful [34], most of the published data supports QPCR based MRD monitoring. One of the limitations in the field is standardization of QPCR MRD monitoring and establishing standards for comparison of QPCR results across institutions and a clear determination of whether the bone marrow or the peripheral blood MRD measurement provided the most useful information.

\section{DECISION MAKING BASED ON MRD}

While the prognostic role of MRD monitoring in CBF is well defined, how the data can influence treatment interventions to improve outcome is not clear. Our group reported on the use of hypomethylating agents (HMA) as a potential maintenance strategy in CBF AML, particularly among patients who have persistent MRD after induction/consolidation and patients whose consolidation therapy is curtailed because of older age or adverse events/treatment related serious side-effects [35]. HMA-based therapy can convert a low MRD positive to negative MRD status and/or possibly prevent progression. This strategy may not be effective for high levels of MRD or rapidly increasing MRD.

Investigators from China used allogeneic stem cell transplant (allo-SCT) as an intervention strategy for patients with $t(8 ; 21)$ and suboptimal MRD response by QPCR (defined as $<3$ log reduction in the bone marrow transcripts). They reported a CIR of $22.1 \%$ with allo-SCT versus $78.9 \%$ with chemotherapy $(P<0.0001$; the DFS was $61.7 \%$ versus $19.6 \%(P=0.001)$ [36]. The MRD-based decision making for suboptimal response to frontline therapy is expected to further evolve in the near future for CBF AML.

\section{DOES ADDITIONAL CYTOGENETIC ABNORMALITIES MATTER}

Additional cytogenetic abnormalities involving chromosomes 8,9 , 21 , and 22 are common in CBF AML. The presence of trisomy 22 and/or loss of a sex chromosome may predict for better outcome in inv16 AML, but this has not been a uniform finding across studies $[5,17,31]$. The presence of additional cytogenetic abnormalities do not predict for outcome in $t(8 ; 21)$ AML [5]. 


\section{THE IMPACT OF CONCOMITANT MUTATIONS ON OUTCOME IN CBF AML}

The presence of KIT mutations (exon 17) has been associated with a higher relapse rate in CBF AML [37]. However, in our analysis, a suboptimal MRD response by QPCR, and not KIT mutation, was best associated with relapse [20]. In other analyses from larger groups of patients treated with $3+7$, the presence of multiple kinase mutations (KIT, RAS, and FLT3 taken together) [38] and a higher allelic burden (but not presence of KIT mutation alone), were associated with higher relapse [39]. The presence of a KIT mutation has not been prognostic in an analysis of pediatric CBF AML data [40]. It is of interest that most often, a KIT mutation is not detectable at relapse among patients with a baseline KIT mutation, raising the question of whether a KIT mutation has a driver role in this context.

More contemporary analyses have reported epigenetic mutations (e.g. ASXL2), kinase mutations (JAK2), and cohesion/ spliceosome mutations at diagnosis to be associated with a higher relapse rate $[14,16]$. Given the strong association of relapse with suboptimal MRD clearance, it will be important to investigate whether any mutation class or combination of mutations is associated with a suboptimal MRD clearance.

\section{INCORPORATING KINASE INHIBITION INTO FRONTLINE THERAPY}

Given the prognostic implication of KIT mutation, adding potent KIT inhibitors like avapritinib or dasatinib into frontline therapy may improve outcome of CBF AML. In a non-randomized trial, the German group reported that the addition of dasatinib into frontline therapy reduced the relapse rate in KIT-mutated CBF AML to levels comparable to non-KIT mutated CBF [41]. CALGB 10801 trial also reported similar results [42]. A possible rationale to add dasatinib or avapritinib to frontline therapy in all CBF AML derives from the observation that KIT is overexpressed in most CBF AML. Randomized trial data to convincingly support the addition of dasatinib have not been reported.

\section{THE ROLE OF ALLOGENEIC STEM CELL TRANSPLANT IN CBF AML}

The general consensus is to reserve allo-SCT for relapsed CBF AML. However, an argument can be made for SCT in first remission for patients with suboptimal MRD clearance, where the expected risk of relapse might be high.

\section{CBF AML IN OLDER/UNFIT PATIENTS}

Patients older than 60 years comprise about $5-15 \%$ of adult CBF AML patients $[8,17,29]$ and have a worse OS $[8,17]$. A French AML Intergroup study evaluated the outcome of CBF AML among patients 60 years or older $(n=147)$. Cytarabine and anthracyclinebased induction chemotherapy resulted in a CR of $80 \%$ with the first course, and $88 \%$ after a second course. The induction mortality was $10 \%$, and the induction failure/resistance rate was only $2 \%$. Post-remission therapy included either maintenance chemotherapy (low-dose cytarabine, methotrexate, and mercaptopurine; $n=72$ ) or intensive consolidation therapy [IDAC/HDAC-based regimen for at least 2 days $(n=48)$, or high-dose melphalan followed by autoSCT $(n=8)]$. After a median follow-up of 48 months, the 5-year probabilities of overall survival (OS) and leukemia-free survival (LFS) were $31 \%$ and $27 \%$, respectively. The 5 -year DFS rate was significantly longer with intensive consolidation compared with low intensity maintenance chemotherapy $(p=0.05)$, and most of the benefit was observed in patients with $\mathrm{t}(8 ; 21)(p=0.007)$ but not in patients with inv $(16) / t(16 ; 16)(p=0.78)$ [43]. Therefore, older patients with CBF AML should be offered intensive post-remission chemotherapy if considered fit to receive such therapy. Given high relapse rate, alternate salvage strategies are needed for patients who are not candidates for intensive therapy.

\section{TREATMENT OF RELAPSED CBF AML}

Salvage intensive chemotherapy has been the norm in relapsed CBF AML. In an analysis of the outcome of 92 patients with relapsed-refractory $C B F A M L$ at $M D$ Anderson, the median survival for patients with inv(16) was 15.6 months (range 10.32-20.88 months) and for patients with $t(8 ; 21) 9$ months (range 3.68-14.32) $(P=0.004)$ [44]. A multivariate analysis showed that $\mathrm{t}(8 ; 21)$ was associated with a higher hazard of death after adjusting for age and stem cell transplant (hazard ratio 1.802; $P=$ 0.02). In an analysis from the French group, a first remission duration of over 1 year and treatment with regimens incorporating GO were associated with better DFS and OS. The CBF AML cytogenetic subset did not impact outcome [45].

\section{SECONDARY OR THERAPY-RELATED CBF AML}

While most cases of CBF-AML are de novo, CBF AML can emerge as part of therapy-related AML. While the outcome of secondary or therapy-related acute promyelocytic leukemia (APL), another member of the good-prognosis AML subsets, is similar to de novo $A P L$, the outcome of secondary or therapy-related CBF AML (tCBF$A M L)$ is significantly worse than de novo $\operatorname{CBF} A M L[46,47]$. The presence of a JAK2 mutation, a poor risk mutation in newly diagnosed CBF AML, is more common in therapy-related CBF AML. In a multi-center data analysis, the t-CBF-AML patients had shorter OS than de novo patients (median 69 vs 190 months, $P=0.038$ ) [46].

\section{CONCLUSIONS}

Although CBF AML is considered a good-risk AML subgroup, given the results from large co-operative groups and SEER data, improving our current therapeutic strategies with use of existing drugs, can potentially improve the outcome substantially. The incorporation of GO should be widely adopted. Fludarabine and cytarabine based frontline regimens provide effective alternatives to $3+7$ (Fig. 1). Monitoring of MRD should also be adopted broadly but requires further standardization. Finally, MRD-based treatment interventions/modification should be investigated systematically.

Current Treatment Algorithm for Core Binding factor Acute Myelogenous Leukemia Consider clinical trial option when possible

\begin{tabular}{|c|c|}
\hline Diagnosis & $\begin{array}{l}\text { Cytogenetics } \\
\text { QPCR for fusion transcript } \\
\text { AML Mutation panel }\end{array}$ \\
\hline Induction & $\begin{array}{l}3+7 \text { or FLAG based } \\
\text { Add GO } \\
\text { QPCR at end of induction }\end{array}$ \\
\hline Consolidation (4-6 cycles) & $\begin{array}{l}\text { HDAC/GO or FLAG/GO } \\
\text { (GO in } 2 \text { of consolidation cycles) } \\
\text { Monitoring: QPCR every 2-3 cycles }\end{array}$ \\
\hline Post consolidation & $\begin{array}{l}\text { Optimal QPCR response:Monitor } \\
\text { Suboptimal response } \\
\text { - ?allo-SCT } \\
\text { - ? HMA+/- venetoclax }\end{array}$ \\
\hline Monitoring frequency & $\begin{array}{l}2-3 \text { months for first } 3 \text { years } \\
\text { Every } 6 \text { months thereafter to complete } 5 \text { years }\end{array}$ \\
\hline
\end{tabular}

Fig. 1 Core binding factor AML treatment and response monitoring algorithm. FLAG fludarabine, cytarabine, GCSF, HDAC high-dose cytarabine, GO gemtuzumab ozogamicin, QPCR quantitative polymerase chain reaction, all-SCT allogeneic stem cell transplant, HMA hypomethylating agent. 


\section{REFERENCES}

1. Byrd JC, Mrózek K, Dodge RK, Carroll AJ, Edwards CG, Arthur DC, et al. Pretreatment cytogenetic abnormalities are predictive of induction success, cumulative incidence of relapse, and overall survival in adult patients with de novo acute myeloid leukemia: results from Cancer and Leukemia Group B (CALGB 8461). Blood. 2002;100:4325-36.

2. Fernandez HF, Sun Z, Yao X, Litzow MR, Luger SM, Paietta EM, et al. Anthracycline dose intensification in acute myeloid leukemia. N Engl J Med. 2009;361:1249-59.

3. Grimwade D, Walker H, Oliver F, Wheatley K, Harrison C, Harrison G, et al. The importance of diagnostic cytogenetics on outcome in AML: analysis of 1,612 patients entered into the MRC AML 10 trial. The Medical Research Council Adult and Children's Leukaemia Working Parties. Blood. 1998;92:2322-33.

4. Schlenk RF, Benner A, Hartmann F, del Valle F, Weber C, Pralle H, et al. Riskadapted postremission therapy in acute myeloid leukemia: results of the German multicenter AML HD93 treatment trial. Leukemia. 2003;17:1521-8.

5. Grimwade D, Hills RK, Moorman AV, Walker H, Chatters S, Goldstone AH, et al. Refinement of cytogenetic classification in acute myeloid leukemia: determination of prognostic significance of rare recurring chromosomal abnormalities among 5876 younger adult patients treated in the United Kingdom Medical Research Council trials. Blood. 2010;116:354-65.

6. Kwong YL, Chan V, Wong KF, Chan TK. Use of the polymerase chain reaction in the detection of AML1/ETO fusion transcript in t(8;21). Cancer. 1995;75:821-5.

7. Tobal K, Johnson PR, Saunders MJ, Harrison CJ, Liu Yin JA. Detection of CBFB/ $\mathrm{MYH} 11$ transcripts in patients with inversion and other abnormalities of chromosome 16 at presentation and remission. Br J Haematol. 1995;91:104-8.

8. Appelbaum FR, Kopecky KJ, Tallman MS, Slovak ML, Gundacker HM, Kim HT, et al. The clinical spectrum of adult acute myeloid leukaemia associated with core binding factor translocations. Br J Haematol. 2006;135:165-73.

9. Mrozek K, Heinonen K, Bloomfield CD. Clinical importance of cytogenetics in acute myeloid leukaemia. Best Pract Res Clin Haematol. 2001;14:19-47.

10. Schlenk RF, Benner A, Krauter J, Büchner T, Sauerland C, Ehninger G, et al. Individual patient data-based meta-analysis of patients aged 16 to 60 years with core binding factor acute myeloid leukemia: a survey of the German Acute Myeloid Leukemia Intergroup. J Clin Oncol. 2004;22:3741-50.

11. Speck NA, Gilliland DG. Core-binding factors in haematopoiesis and leukaemia. Nat Rev Cancer. 2002;2:502-13.

12. Stengel KR. et al. Definition of a small core transcriptional circuit regulated by AML1-ETO. Mol Cell. 2021;81:530-45.

13. Vangala RK, Heiss-Neumann MS, Rangatia JS, Singh SM, Schoch $C$, Tenen DG, et al. The myeloid master regulator transcription factor PU.1 is inactivated by AML1-ETO in t(8;21) myeloid leukemia. Blood. 2003;101:270-7.

14. Faber ZJ, Chen X, Gedman AL, Boggs K, Cheng J, Ma J, et al. The genomic landscape of core-binding factor acute myeloid leukemias. Nat Genet. 2016;48:1551-6.

15. Sood R, Hansen NF, Donovan FX, Carrington B, Bucci D, Maskeri B, et al. Somatic mutational landscape of $A M L$ with inv(16) or $t(8 ; 21)$ identifies patterns of clonal evolution in relapse leukemia. Leukemia. 2016;30:501-4.

16. Christen F, Hoyer K, Yoshida K, Hou HA, Waldhueter N, Heuser M, et al. Genomic landscape and clonal evolution of acute myeloid leukemia with $t(8 ; 21)$ : an international study on 331 patients. Blood. 2019;133:1140-51.

17. Marcucci G, Mrózek K, Ruppert AS, Maharry K, Kolitz JE, Moore JO, et al. Prognostic factors and outcome of core binding factor acute myeloid leukemia patients with $t(8 ; 21)$ differ from those of patients with inv(16): a Cancer and Leukemia Group B study. J Clin Oncol. 2005;23:5705-17.

18. Duployez N, Marceau-Renaut A, Boissel N, Petit A, Bucci M, Geffroy S, et al. Comprehensive mutational profiling of core binding factor acute myeloid leukemia. Blood. 2016;127:2451-9.

19. Itzykson R, Duployez N, Fasan A, Decool G, Marceau-Renaut A, Meggendorfer M, et al. Clonal interference of signaling mutations worsens prognosis in corebinding factor acute myeloid leukemia. Blood. 2018;132:187-96.

20. Boddu P, Gurguis C, Sanford D, Cortes J, Akosile M, Ravandi F, et al. Response kinetics and factors predicting survival in core-binding factor leukemia. Leukemia. 2018;32:2698-701.

21. Yin JA, O'Brien MA, Hills RK, Daly SB, Wheatley K, Burnett AK. Minimal residual disease monitoring by quantitative RT-PCR in core binding factor AML allows risk stratification and predicts relapse: results of the United Kingdom MRC AML-15 trial. Blood. 2012;120:2826-35.

22. Weisser M, Haferlach C, Hiddemann W, Schnittger S. The quality of molecular response to chemotherapy is predictive for the outcome of AML1-ETO-positive AML and is independent of pretreatment risk factors. Leukemia. 2007;21:1177-82.

23. Borthakur G, Cortes JE, Estey EE, Jabbour E, Faderl S, O'Brien S, et al. Gemtuzumab ozogamicin with fludarabine, cytarabine, and granulocyte colony stimulating factor (FLAG-GO) as front-line regimen in patients with core binding factor acute myelogenous leukemia. Am J Hematol. 2014;89:964-8.

24. Borthakur G, Kantarjian H, Wang X, Plunkett WK Jr, Gandhi VV, Faderl S, et al. Treatment of core-binding-factor in acute myelogenous leukemia with fludarabine, cytarabine, and granulocyte colony-stimulating factor results in improved event-free survival. Cancer. 2008;113:3181-5.

25. Burnett AK, Hills RK, Milligan D, Kjeldsen L, Kell J, Russell NH, et al. Identification of patients with acute myeloblastic leukemia who benefit from the addition of gemtuzumab ozogamicin: results of the MRC AML15 trial. J Clin Oncol. 2011;29:369-77.

26. Gandhi V, Estey E, Keating MJ, Plunkett W. Fludarabine potentiates metabolism of cytarabine in patients with acute myelogenous leukemia during therapy. J Clin Oncol. 1993;11:116-24.

27. Burnett AK, Russell NH, Hills RK, Hunter AE, Kjeldsen L, Yin J, et al. Optimization of chemotherapy for younger patients with acute myeloid leukemia: results of the medical research council AML15 trial. J Clin Oncol. 2013;31:3360-8.

28. Hills RK, Castaigne S, Appelbaum FR, Delaunay J, Petersdorf S, Othus M, et al. Addition of gemtuzumab ozogamicin to induction chemotherapy in adult patients with acute myeloid leukaemia: a meta-analysis of individual patient data from randomised controlled trials. Lancet Oncol. 2014;15:986-96.

29. Byrd JC, Dodge RK, Carroll A, Baer MR, Edwards C, Stamberg J, et al. Patients with $t(8 ; 21)(q 22 ; q 22)$ and acute myeloid leukemia have superior failure-free and overall survival when repetitive cycles of high-dose cytarabine are administered. J Clin Oncol. 1999;17:3767-75.

30. Byrd JC, Ruppert AS, Mrózek K, Carroll AJ, Edwards CG, Arthur DC, et al. Repetitive cycles of high-dose cytarabine benefit patients with acute myeloid leukemia and inv(16)(p13q22) or $t(16 ; 16)(p 13 ; q 22)$ : results from CALGB 8461. J Clin Oncol. 2004:22:1087-94.

31. Delaunay J, Vey N, Leblanc T, Fenaux P, Rigal-Huguet F, Witz F, et al. Prognosis of inv $(16) / t(16 ; 16)$ acute myeloid leukemia $(A M L)$ : a survey of 110 cases from the French AML Intergroup. Blood. 2003;102:462-9.

32. Marcucci G, Caligiuri MA, Döhner $H$, Archer KJ, Schlenk RF, Döhner $K$, et al. Quantification of CBFbeta/MYH11 fusion transcript by real time RT-PCR in patients with INV(16) acute myeloid leukemia. Leukemia. 2001;15:1072-80.

33. Höllein A, Jeromin S, Meggendorfer M, Fasan A, Nadarajah N, Kern W, et al. Minimal residual disease (MRD) monitoring and mutational landscape in AML with RUNX1-RUNX1T1: a study on 134 patients. Leukemia. 2018;32:2270-4.

34. Ouyang J, Goswami M, Peng J, Zuo Z, Daver N, Borthakur G, et al. Comparison of multiparameter flow cytometry immunophenotypic analysis and quantitative RTPCR for the detection of minimal residual disease of core binding factor acute myeloid leukemia. Am J Clin Pathol. 2016;145:769-77.

35. Ragon BK, Daver N, Garcia-Manero G, Ravandi F, Cortes J, Kadia T, et al. Minimal residual disease eradication with epigenetic therapy in core binding factor acute myeloid leukemia. Am J Hematol. 2017;92:845-50.

36. Zhu HH, Zhang XH, Qin YZ, Liu DH, Jiang $H$, Chen $H$, et al. MRD-directed risk stratification treatment may improve outcomes of $t(8 ; 21) A M L$ in the first complete remission: results from the AML05 multicenter trial. Blood. 2013;121:4056-62.

37. Paschka P, Marcucci G, Ruppert AS, Mrózek K, Chen H, Kittles RA, et al. Adverse prognostic significance of KIT mutations in adult acute myeloid leukemia with inv (16) and t(8;21): a Cancer and Leukemia Group B Study. J Clin Oncol. 2006;24:3904-11.

38. Jourdan E, Boissel N, Chevret S, Delabesse E, Renneville A, Cornillet P, et al. Prospective evaluation of gene mutations and minimal residual disease in patients with core binding factor acute myeloid leukemia. Blood. 2013;121:2213-23.

39. Allen C, Hills RK, Lamb K, Evans C, Tinsley S, Sellar R, et al. The importance of relative mutant level for evaluating impact on outcome of KIT, FLT3 and CBL mutations in core-binding factor acute myeloid leukemia. Leukemia. 2013;27:1891-901.

40. Pollard JA, Alonzo TA, Gerbing RB, Ho PA, Zeng R, Ravindranath Y, et al. Prevalence and prognostic significance of KIT mutations in pediatric patients with core binding factor AML enrolled on serial pediatric cooperative trials for de novo AML. Blood. 2010;115:2372-9.

41. Paschka P, Schlenk RF, Weber D, Benner A, Bullinger L, Heuser M, et al. Adding dasatinib to intensive treatment in core-binding factor acute myeloid leukemiaresults of the AMLSG 11-08 trial. Leukemia. 2018;32:1621-30.

42. Marcucci G, Geyer S, Laumann K, Zhao W, Bucci D, Uy GL, et al. Combination of dasatinib with chemotherapy in previously untreated core binding factor acute myeloid leukemia: CALGB 10801. Blood Adv. 2020;4:696-705.

43. Prébet $T$, Boissel $N$, Reutenauer $S$, Thomas $X$, Delaunay J, Cahn JY, et al. Acute myeloid leukemia with translocation $(8 ; 21)$ or inversion $(16)$ in elderly patients treated with conventional chemotherapy: a collaborative study of the French CBF-AML intergroup. J Clin Oncol. 2009;27:4747-53.

44. Khan M, Cortes J, Qiao W, Alzubaidi MA, Pierce SA, Ravandi F, et al. Outcomes of patients with relapsed core binding factor-positive acute myeloid leukemia. Clin Lymphoma Myeloma Leuk. 2018;18:e19-e25.

45. Hospital MA, Prebet T, Bertoli S, Thomas X, Tavernier E, Braun T, et al. Corebinding factor acute myeloid leukemia in first relapse: a retrospective study from the French AML Intergroup. Blood. 2014;124:1312-9. 
46. Rogers HJ, Wang X, Xie Y, Davis AR, Thakral B, Wang SA, et al. Comparison of therapy-related and de novo core binding factor acute myeloid leukemia: a bone marrow pathology group study. Am J Hematol. 2020;95:799-808.

47. Borthakur G, Lin E, Jain N, Estey EE, Cortes JE, O'Brien S, et al. Survival is poorer in patients with secondary core-binding factor acute myelogenous leukemia compared with de novo core-binding factor leukemia. Cancer 2009;115:3217-21.

\section{COMPETING INTERESTS}

The authors declare no competing interests.

\section{ADDITIONAL INFORMATION}

Correspondence and requests for materials should be addressed to G.B.

Reprints and permission information is available at http://www.nature.com/reprints
Publisher's note Springer Nature remains neutral with regard to jurisdictional claims in published maps and institutional affiliations.

(i) Open Access This article is licensed under a Creative Commons Attribution 4.0 International License, which permits use, sharing, adaptation, distribution and reproduction in any medium or format, as long as you give appropriate credit to the original author(s) and the source, provide a link to the Creative Commons license, and indicate if changes were made. The images or other third party material in this article are included in the article's Creative Commons license, unless indicated otherwise in a credit line to the material. If material is not included in the article's Creative Commons license and your intended use is not permitted by statutory regulation or exceeds the permitted use, you will need to obtain permission directly from the copyright holder. To view a copy of this license, visit http://creativecommons.org/licenses/by/4.0/.

(c) The Author(s) 2021 